\title{
OS GRANDES ACIDENTES DE CONSUMO E A CUSTOMIZAÇÃO DAS SOLUÇÕES CONSENSUAIS PARA OS CONFLITOS ${ }^{1}$
}

\section{MAJOR CONSUMER ACCIDENTS AND CUSTOMIZATION OF CONSENSUAL SOLUTIONS OF DISPUTES}

Eduardo Chow de Martino Tostes

Defensor Público. Professor convidado dos cursos de PósGraduação lato sensu da UFF, da PUC-Rio e da UCAM. Mestre e Doutorando em Direito pela UFF. Rio de Janeiro/RJ.

Leonardo Faria Schenk

Advogado. Professor Adjunto de Direito Processual Civil da UERJ. Mestre e Doutor em Direito Processual pela UERJ. Rio de Janeiro/RJ. E-mail: leonarco.schenk@ pcpcadv.com.br

RESUMO: O estudo apresenta a experiência do Núcleo de Defesa do Consumidor da Defensoria Pública do Estado no Rio de Janeiro na busca de soluções customizadas para os conflitos resultantes dos grandes acidentes de consumo ocorridos no último lustro, com a participação das empresas responsáveis e em colaboração com diversos atores públicos e privados, que prestigia a construção de uma solução consensual a partir da identificação das reais necessidades das pessoas afetadas. Como se verá, as diretrizes observadas na construção da melhor solução consensual conferem ampla legitimidade ao método e asseguram a entrega de uma resposta rápida e efetiva para as vítimas.

PALAVRAS-CHAVE: Acesso à justiça. Grandes acidentes de consumo. Método consensual de resolução dos conflitos. Customização das soluções.

ABSTRACT: The study presents the experience of the Consumer Defense Nucleus of the Public Defender's Office of the State of Rio de Janeiro in the search for customized solutions

\footnotetext{
${ }^{1}$ Artigo recebido em 06/10/2020 e aprovado em 15/12/2020.
} 
to disputes resulting from major accidents affecting consumers, with the participation of the responsible companies and collaboration of various public and private actors, to construct consensual solutions based on identifying the real needs of the affected people. As seen, the guidelines observed in formulating consensual solutions give wide legitimacy to the method and assure the delivery of a rapid and effective response to the victims.

KEY WORDS: Access to justice. Major consumer accidents. Consensual dispute resolution. Customization of solutions.

\section{1 - CONSIDERAÇÕES INICIAIS}

O presente estudo busca instigar a reflexão e indicar os rumos para o desenvolvimento de um modelo abrangente e eficaz de resolução consensual dos conflitos resultantes dos grandes acidentes de consumo que prestigia a pacificação social, com a entrega de uma resposta rápida e efetiva para as vítimas.

Defende-se que a adoção de uma conduta cooperativa pelos envolvidos nos grandes acidentes de consumo, por todos eles, com a participação dos legítimos representantes dos interesses das coletividades afetadas, pode beneficiar diretamente as vítimas e também, em certos aspectos, as empresas responsáveis.

O objeto do estudo é delimitado pelas situações concretas verificadas em grandes acidentes de consumo ocorridos no Estado do Rio de Janeiro dos anos de 2015 a 2019 e que tiveram a solução consensual dos conflitos alcançada com a participação do Núcleo de Defesa do Consumidor da Defensoria Pública do Estado do Rio de Janeiro - NUDECONRJ.

Os métodos de investigação empregados foram o genealógico de Foucault ${ }^{2}$ e o dedutivo, com o uso das ferramentas metodológicas de análise de casos, a partir dos dados

\footnotetext{
${ }^{2}$ Que busca compreender a emergência de configurações singulares de sujeitos, objetos e significações nas relações de poder, associando o exame de práticas discursivas e não-discursivas. Sobre o tema, cf.: FOUCAULT, Michel. Microfísica do Poder. 26. ed. São Paulo: Graal, 2013, p. 21, 26 e 32; e MORAES, Marcos Vinicius Malheiros. GENEALOGIA - MICHEL FOUCAULT. Enciclopédia de Antropologia. São Paulo: Universidade de São Paulo, Departamento de Antropologia, 2018. Disponível em: http://ea.fflch.usp.br/conceito/genealogia-michel-foucault. Acesso em 10 abril de 2020.
} 
públicos disponíveis, principalmente, nos processos administrativos públicos instaurados e mantidos pela Defensoria Pública do Estado do Rio de Janeiro e nos processos judiciais em tramitação no Tribunal de Justiça do mesmo Estado, além da pesquisa bibliográfica.

O texto está estruturado em sete partes, começando pela exposição dos casos concretos. Em seguida, são firmados os pilares para o desenvolvimento de um possível modelo de resolução consensual dos conflitos decorrentes dos grandes acidentes de consumo, com a avaliação dos benefícios para as vítimas e também para as empresas envolvidas. Ao final, há um convite à reflexão e ao desenvolvimento do tema.

\section{2 - BREVE RELATO DOS GRANDES ACIDENTES DE CONSUMO OCORRIDOS NO ÚLTIMO LUSTRO NO ESTADO DO RIO DE JANEIRO}

Os grandes acidentes de consumo têm provocado cicatrizes na vida das pessoas na atualidade.

A complexidade das suas causas, a vastidão dos seus efeitos e a postura dos responsáveis em não raras vezes acabam submetendo as vítimas desses graves eventos a uma dupla penalização: primeiro, ao sofrimento decorrente da perda ou abalo de vidas humanas e aos prejuízos em razão da degradação dos mais diversos bens materiais e imateriais; e, segundo, às angustias e prejuízos relacionados à exigência, imposta às vítimas, de buscar no Poder Judiciário socorro para a satisfação das suas necessidades imediatas, como exemplificam os tratamentos médicos urgentes e o recebimento de aluguéis ou pensões, e para o recebimento de uma justa indenização.

Os exemplos, infelizmente, são muitos.

O leading case aqui estudado data de 5 de janeiro de 2015, quando ocorreu uma colisão entre dois trens da Supervia no ramal Japeri, que corta a Baixada Fluminense, deixou mais de 150 (cento e cinquenta) passageiros feridos. ${ }^{3}$

\footnotetext{
${ }^{3}$ O Globo, matéria intitulada "Choque entre dois trens da SuperVia na Baixada deixa mais de 140 passageiros feridos", publicada em 5/1/2015.
} 
Pouco mais de um mês depois, em 18 de fevereiro de 2015, um ônibus da Viação Mauá pegou fogo após uma colisão no bairro Santa Catarina, em São Gonçalo, deixando pelo menos 8 (oito) passageiros mortos e outros 9 (nove) feridos. ${ }^{4}$

Em 3 de março do mesmo ano, o rompimento de uma adutora da Companhia Estadual de Água e Esgoto - CEDAE em Nova Iguaçu, na Baixada Fluminense, comprometeu a estrutura das casas e deixou pelo menos 50 (cinquenta) famílias desalojadas. ${ }^{5}$

Em 15 de julho de 2015, após a embarcação da CCR Barcas que fazia a travessia da Baía de Guanabara entre a capital fluminense e a cidade de Niterói se chocar contra o cais na Praça XV pelo menos 12 (doze) pessoas ficaram feridas. ${ }^{6}$

Um acidente em Paraty, na Costa Verde fluminense, com ônibus da Concessionária Colitur, ocorrido em 6 de setembro de 2015, deixou 15 (quinze) mortos e mais de 60 (sessenta) pessoas feridas. ${ }^{7}$

No ano seguinte, em 5 de abril de 2016, um vazamento na rede de gás de responsabilidade da CEG provocou uma forte explosão em um prédio na Fazenda Botafogo, bairro da cidade do Rio de Janeiro, que resultou na morte de 5 (cinco) pessoas e deixou pelo menos outras 9 (nove) feridas, além de comprometer a estrutura dos prédios do conjunto habitacional com mais de 10 mil moradores. ${ }^{8}$

Em 8 de novembro de 2017, mais de 100 (cem) pessoas ficaram desalojadas após a abertura de uma cratera às margens da BR-040, em Petrópolis, rodovia federal então administrada pela Concer. ${ }^{9}$

\footnotetext{
${ }^{4}$ G1, matéria intitulada “Ônibus pega fogo após colisão e deixa mortos em São Gonçalo, RJ”, publicada em $18 / 2 / 2015$.

5 Agência Brasil, matéria intitulada "Cedae assina acordo para indenizar vítimas de rompimento de adutora", publicada em 5/3/2015.

${ }^{6}$ Estadão, matéria intitulada “Acidente em barca deixa 12 pessoas feridas no centro do Rio", publicada em $15 / 7 / 2015$.

${ }^{7}$ G1, matéria intitulada “Acidente com ônibus deixa 15 mortos em Paraty”, publicada em 6/9/2015.

${ }^{8}$ Estadão, matéria intitulada “Explosão em apartamento mata 5 em Fazenda Botafogo”, publicada em 5/4/2016.

${ }^{9}$ SFn Notícias, matéria intitulada "Mais de 100 desalojados após abertura de cratera às margens da BR-040, em Petrópolis", publicada em 8/11/2017.
} 
No dia 24 de janeiro de 2018 houve novo rompimento de uma adutora da Companhia Estadual de Água e Esgoto - CEDAE, destruindo os lares de aproximadamente uma centena de pessoas. ${ }^{10}$

Em 13 de agosto de 2018, o rompimento de outra adutora da CEDAE afetou a vida de centenas de pessoas em Nova Iguaçu, na Baixada Fluminense. ${ }^{11}$

Para encerrar a lista exemplificativa de eventos, em 27 de fevereiro de 2019 houve outro acidente com trens da Supervia, com a infeliz ocorrência de danos aos passageiros e a morte do condutor da composição afetada. ${ }^{12}$

A realidade da sociedade fluminense, assolada por inúmeros outros acidentes de consumo no último lustro, bem retrata os dramas humanos por eles provocados.

Os tristes exemplos se espalham pelo país, numa sucessão lamentável e quase infinita de óbitos e prejuízos, os mais recentes ofuscando na grande mídia a visibilidade dos anteriores, ${ }^{13}$ sem que as vítimas e suas famílias, na grande maioria dos casos, encontrem conforto e recebam, em tempo razoável, a justa reparação. ${ }^{14}$

Nesse contexto, é fundamental que haja o desenvolvimento de um espaço para atuação madura e colaborativa dos agentes públicos e das empresas envolvidos nesses tipos de conflitos na busca de soluções efetivas, com a construção de uma adequada rede de participação, incluindo os demais legitimados coletivos.

\footnotetext{
${ }^{10}$ Jornal O Dia, matéria intitulada "No dia seguinte à explosão de adutora, hora da faxina em 30 casas", publicada em 21/01/2018.

${ }^{11}$ Jornal BandNews intitulada "Defensoria Pública e Cedae fazem acordo para auxiliar vítimas de rompimento de adutora - Segundo a Defesa Civil de Nova Iguaçu, 268 famílias, num total de 718 pessoas, foram atingidas pelo acidente", publicada em 16/10/2018.

${ }^{12}$ Jornal G1, matéria intitulada" Colisão entre trens deixa 9 feridos no Rio; resgate de maquinista durou mais de 7 horas", publicada em 27/02/2019.

${ }^{13}$ A cobertura da mídia não raro transforma todos em plateia, em um auditório ávido por realizar o julgamento da conduta dos envolvidos. Nas lições de Perelman, "É por essa razão que, em matéria de retórica, parece preferível definir o auditório como o conjunto daqueles que o orador quer influenciar com sua argumentação. Cada orador pensa, de uma forma mais ou menos consciente, naqueles que procuram persuadir e que constituem o auditório ao qual se dirigem seus discursos". PERELMAN, Chaïm; OLBRECHTS-TYTECA, Lucie; COELHO, Fábio Olhôa. Tratado da argumentação: a nova retórica. Martins Fontes, 1996. p. 22.

${ }^{14}$ No âmbito de uma democracia participativa, a opinião pública tem muitas funções a desempenhar. Nos respectivos meios de comunicação - desde a conversa de bar, passando pela imprensa escrita, falada e televisionada, até as ciências, simpósios e academias especializadas, sem falar nas iniciativas populares -, a opinião pública não apenas é um fórum em que se podem exprimir interesses e opiniões, mas também uma arena em que se luta por influência e poder. HÖFFE, Otfried. A Democracia no mundo de hoje. Tradução de Tito Lívio Cruz Romão. São Paulo: Martins Fontes, 2005, p. 132.
} 


\section{3 - A IDENTIFICAÇÃO DE INICIATIVAS PIONEIRAS PARA A ADEQUADA SOLUÇÃO DOS CONFLITOS}

Pela complexidade das causas e vastidão dos seus graves efeitos, os grandes acidentes de consumo, além da forte comoção social que provocam, ${ }^{15}$ sempre constituem uma oportunidade para o desenvolvimento de técnicas extrajudiciais de solução dos conflitos.

Foi o que se viu, por exemplo, com o Programa de Indenização extrajudicial para os familiares das vítimas brasileiras do Voo 447 da Air France, que caiu no oceano Atlântico em 31 de maio de 2009, com a participação da empresa aérea e sua seguradora, dos familiares das vítimas, de representantes do Ministério da Justiça, do Ministério Público e do Procon do Estado do Rio de Janeiro. ${ }^{16}$

Antes disso, também para o acidente com o Voo JJ 3054 da TAM, ocorrido em 17 de julho de 2007, cuja aeronave se chocou com um prédio no final da pista do aeroporto de Congonhas, em São Paulo, após não conseguir aterrissar em segurança, uma Câmara de Indenização extrajudicial havia sido instituída, por iniciativa dos órgãos que integravam o Sistema Nacional de Defesa do Consumidor, dentre eles o Ministério Público, a Defensoria Pública e o Procon do Estado de São Paulo, da empresa aérea e suas seguradoras, com objetivo de facilitar a resolução dos conflitos extrajudicialmente e a efetiva reparação dos danos. ${ }^{17}$

Voltando os olhos para a realidade da sociedade fluminense no último lustro, o que há de relevante, e diferente, nas técnicas empregadas para a tentativa de adequada solução dos conflitos resultantes dos grandes acidentes de consumo?

\footnotetext{
${ }^{15}$ Normalmente proporcional à cobertura que a mídia confere ao caso desde o dia do evento até o momento da divulgação da solução encontrada para o conflito pelas partes.

${ }^{16}$ Para mais informações, cf.: ARAÚJO, Nadia de; FÜRST, Olivia. Um exemplo brasileiro do uso da mediação em eventos de grande impacto: o programa de indenização do voo 447. Revista de Direito do Consumidor, vol. 91/2014, p. 337, Jan/2014.

${ }^{17}$ Sobre a experiência, cf.: LEAL, Leonardo José Peixoto. Acidentes de consumo e resolução extrajudicial. Trabalho publicado nos Anais do XVIII Congresso Nacional do CONPEDI, realizado em São Paulo/SP nos dias $04,05,06$ e 07 nov/2009.

Sobre a recente criação de entidades de infraestrutura específica para dar cumprimento a negócios jurídicos e a decisões judiciais nos grandes acidentes de consumo, iniciativa também bastante interessante e em franco desenvolvimento no Brasil, cf.: CABRAL, Antonio do Passo; ZANETI JR., Hermes. Entidades de infraestrutura específica para a resolução de conflitos coletivos: as claims resolution facilities e sua aplicabilidade no Brasil. São Paulo: Revista de Processo, vol. 287, Jan/2019, p. 445-483.
} 
Em outras palavras, o que todos os graves acidentes de consumo narrados em rol exemplificativo no item anterior, ocorridos no Estado do Rio de Janeiro, têm em comum a merecer reflexão sob o enfoque do amplo acesso à justiça, em sua feição atual, sobretudo a partir da tomada de consciência de que ao Poder Judiciário cabe um papel de destaque na solução dos conflitos de interesses, mas não a exclusividade na busca de soluções que entreguem aos interessados, em tempo absolutamente razoável, soluções aceitáveis segundo a avaliação de todos os envolvidos?

A resposta é que em todos aqueles acidentes ocorridos no território fluminense foi possível notar a atuação e o protagonismo do Núcleo de Defesa do Consumidor da Defensoria Pública do Estado do Rio de Janeiro (NUDECON-RJ), em conjunto ou não com outros legitimados coletivos, com a participação ativa das empresas envolvidas, no desenvolvimento de um método abrangente e eficaz de solução extrajudicial das controvérsias, que passa por técnicas próprias da mediação e da conciliação, mas não se esgota nelas.

A ausência de identificação clara e segura das vítimas do acidente, não havendo, por exemplo, uma lista de passageiros dos trens envolvidos nas colisões ou dos moradores afetados pelos vazamentos das adutoras; e a elevada vulnerabilidade da população afetada, com a consequente potencialização dos efeitos danosos do acidente, constituem características que permitem distinguir a iniciativa ora em estudo daquelas desenvolvidas especificamente para os acidentes aéreos.

Também a forma de atuação estratégica da Defensoria Pública do Estado do Rio de Janeiro para a tentativa de resolução dos conflitos surgidos a partir dos grandes acidentes de consumo revela um agir diferenciado que busca a articulação direta com todas as partes envolvidas, em especial as vítimas, seus representantes adequados, ${ }^{18}$ as empresas responsáveis, os órgãos públicos fiscalizadores, as Casas Legislativas, ficando o Poder Judiciário como alternativa final.

\footnotetext{
${ }^{18}$ Sobre o tema: "Ocorre que a sociedade brasileira continua a evoluir e o faz mais rapidamente do que a legislação, fato que é de conhecimento geral. Isso implica o aumento da complexidade das relações jurídicas, que não se limitam a conflitos particulares, mas envolvem a coletividade, tanto que os interesses tutelados são chamados de trans, supra ou metaindividuais. Em decorrência do surgimento destes, houve uma alteração também na relação processual, que, mais complexa, implicou a necessidade de ampliação dos mecanismos de acesso à justiça aos ditos "conflitos de massa". MADERS, Angelita Maria. $\mathrm{O}$ acesso à justiça nas relações negociais públicas e privadas: a tutela dos direitos difusos e coletivos pela defensoria pública por meio da ação civil pública. Revista do Direito Público, v. 6, n. n. 3, 2011, p. 25-26.
} 
É preciso que os legitimados coletivos passem a visualizar, diante das complexas variáveis que um grande acidente de consumo revela, as múltiplas e efetivas oportunidades de solução dos conflitos, sempre a partir da perspectiva dos vulneráveis, afastando o Poder Judiciário da primeira opção no leque de sua atuação.

É fundamental, também, que as empresas envolvidas reconheçam no legitimado coletivo a capacidade institucional para resolver de forma adequada e razoável os conflitos, por completo e em definitivo.

Como se verá a seguir, a iniciativa em estudo, que foi finalista da $13^{\mathrm{a}}$ Edição do Prêmio Innovare em 2016 e recebeu Menção Honrosa na Categoria Defensoria Pública, tem como traços marcantes a busca de um acordo que possa oferecer às vítimas do acidente de consumo o melhor resultado possível, no menor tempo disponível, dentro de parâmetros indenizatórios fixados pelas partes com boa-fé e transparência, seguido do engajamento de todos os envolvidos na implementação das medidas concretas voltadas à satisfação dos interesses dos reais prejudicados, tudo sem que se faça necessária a ida ao Poder Judiciário e o aguardo, tormentoso, da sua resposta.

\section{4 - A FIXAÇÃO DAS BASES INICIAIS PARA O MODELO DE CUSTOMIZAÇÃO DAS SOLUÇÕES CONSENSUAIS}

O acidente ocorrido em 2015 com dois trens da Supervia, narrado acima, possibilitou a estruturação das bases para o emprego da metodologia destinada à customização da solução consensual abrangente e eficaz dos conflitos decorrentes dos grandes acidentes de consumo. $^{19}$

Naquela oportunidade, como foi amplamente noticiado, ${ }^{20} \mathrm{em}$ menos de 48 horas após o evento, um Termo de Ajustamento de Conduta havia sido firmado entre a empresa e a

\footnotetext{
${ }^{19}$ Os autores do presente estudo participaram ativamente do processo de negociação e de definição das bases do acordo (Termo de Ajustamento de Conduta - TAC), com a estruturação inicial do método e das diretrizes nele aplicáveis. Também participaram da arquitetura jurídica deste complexo negócio jurídico coletivo a Defensora Pública e Coordenadora do NUDECON-RJ, Patrícia Cardoso Tavares, e o Diretor Jurídico da empresa à época, Marcelo Ferreira Franco.

${ }^{20}$ Cf.: Agência Brasil, matéria intitulada "Defensoria quer indenização para vítimas de acidente de trens no Rio", publicada em 6/1/2015; Agência Brasil, matéria intitulada "Acordo define indenizações às vítimas de acidente de trens no Rio", publicada em 7/1/2015; Estado de Direito, matéria intitulada "Acordo define indenizações às vítimas de acidente de trens no Rio", publicada em 8/1/2015.
} 
Defensoria Pública do Estado do Rio de Janeiro, com a intervenção da Agência Reguladora e da Secretaria de Transportes estaduais, para viabilizar a reparação dos mais diversos danos sofridos pelos passageiros.

O instrumento previu, de modo abrangente e sem a identificação inicial das vítimas, por exemplo, que as indenizações pelos danos materiais seriam aferidas caso a caso, a partir da comprovação dos prejuízos pela vítima do acidente.

A indenização pelo dano moral individual mereceu especial atenção e foi definida no instrumento em níveis variados, conforme a gravidade da lesão demonstrada e do quadro geral da vítima, com a oferta de valores de indenização que tomaram por base as condenações impostas pelo Poder Judiciário fluminense em casos semelhantes nos anos anteriores.

A compensação pelo dano moral coletivo se deu in natura, com a distribuição de 100 mil bilhetes aos passageiros nos ramais da linha férrea impactados diretamente pelo acidente. $^{21}$

A necessidade específica, verificada na ocasião, de tratamento médico e do seu custeio pela empresa poderia ser aferida, havendo controvérsia sobre a causa e a extensão dos danos, com a nomeação de uma junta médica composta por profissionais que seriam indicados pelas partes para a realização de uma perícia médica extrajudicial.

A preocupação com a configuração da qualidade de vítima, evitando, com isso, a habilitação de pessoas oportunistas que não estiveram envolvidas no acidente, foi solucionada com o envio de ofício, pela Defensoria Pública, aos centros médicos e postos de saúde responsáveis pelos atendimentos de urgência na região do acidente para o fornecimento da lista nominal das pessoas atendidas nas horas seguintes ao evento.

Outra preocupação, ligada à sobreposição dos órgãos e entidades legitimados à defesa coletiva dos consumidores, o que poderia ocasionar o ajuizamento de ações coletivas diversas tendo o mesmo acidente como causa de pedir, foi remediada com o envio de ofício, também pela Defensoria Pública, a todos os legitimados coletivos do Estado, dando-lhes ciência dos termos do acordo firmado.

\footnotetext{
${ }^{21}$ Em valores atuais, a compensação ajustada para os danos morais coletivos representaria $\mathrm{R} \$ 470.000,00$ (considerando a tarifa ferroviária de $\mathrm{R} \$ 4,70$ vigente em 2020), que foram entregues de forma rápida e consensual para a população diretamente afetada.
} 
Fechado o acordo em menos de 48 horas contadas da ocorrência do acidente, a sua ampla divulgação na imprensa permitiu que a segunda etapa, voltada à reparação efetiva das vítimas, tivesse início.

Na segunda etapa, funcionários da Defensoria Pública e da empresa atuaram em conjunto atendendo as pessoas interessadas, para confirmar a sua qualidade de vítima, os prejuízos materiais por elas efetivamente sofridos, a adequação do valor da indenização pelos danos materiais e morais, bem como a necessidade ou não de tratamento de saúde, ${ }^{22}$ após o que, havendo a concordância livre e consciente da vítima, que neste ato era assistida pela Defensoria Pública, um termo individual de acordo e quitação era firmado, ao que se seguia o início do prazo para o pagamento das indenizações.

A liberdade de escolha das vítimas era uma condição do acordo global. Elas poderiam aceitar as indenizações ou decidir pela ida ao Poder Judiciário, com a assistência da própria Defensoria Pública, se presentes os fatores que autorizam a atuação.

Questões práticas e jurídicas relacionadas ao tempo médio de espera pela solução judicial, ao valor médio das indenizações pagas em casos semelhantes por ordem do Poder Judiciário, dentre outras, eram claramente esclarecidas às vítimas, permitindo que a sua escolha se desse com base no maior número possível de informações úteis.

No caso piloto, o sucesso da iniciativa foi tão expressivo que, pelo que se tem notícia, de um universo de mais de 150 (cento e cinquenta) vítimas socorridas e levadas aos hospitais da região, a pesquisa revelou não ter chegado a 10 (dez) o número de ações individuais ajuizadas pelas vítimas. ${ }^{23}$ Além disso, não há registro do ajuizamento de ação civil pública por outro legitimado coletivo em defesa dos consumidores com relação ao mesmo acidente.

Os resultados alcançados permitiram que a Defensoria Pública do Estado do Rio de Janeiro fincasse as bases para a consolidação de um método abrangente e eficaz de solução extrajudicial das controvérsias derivadas dos grandes acidentes de consumo que viria a ser replicado, com sucesso, em diversos outros eventos da mesma natureza - a exemplo de todos os acidentes de consumo narrados acima - não só no Estado do Rio de Janeiro como também em diversos outros Estados da Federação.

\footnotetext{
22 O tratamento figurava como condição sine qua non para a concretização do acordo, não apenas pelo necessário cuidado com a saúde, como também pelas repercussões na extensão do dano moral e do dano material.

${ }^{23}$ A pesquisa envolveu a consulta ao sítio do TJRJ e aos registros do NUDECON-RJ.
} 


\section{5 - AS DIRETRIZES MÍNIMAS OBSERVADAS NO DESENHO CONCRETO DAS SOLUÇÕES CONSENSUAIS}

A observação do emprego reiterado, pela Defensoria Pública do Estado do Rio de Janeiro, da metodologia de resolução extrajudicial dos litígios decorrentes dos grandes acidentes de consumo permite identificar quais foram e são as diretrizes mínimas e fundamentais que sustentam a iniciativa e contribuem para o seu sucesso.

Com a pesquisa, foram identificadas cinco diretrizes fundamentais, a saber: a) mapeamento imediato da realidade; b) reparação justa e abrangente; c) boa-fé e transparência; d) liberdade de escolha orientada; e e) engajamento e velocidade da resposta.

\section{A) MAPEAMENTO IMEDIATO DA REALIDADE}

$\mathrm{O}$ mapeamento imediato da realidade constitui um pilar fundamental para o sucesso das etapas seguintes da metodologia. Por meio dele, os representantes das partes envolvidas devem, sempre que possível, de forma conjunta e colaborativa, comparecer ao local do acidente de consumo, logo após a sua ocorrência, para identificar as vítimas e os possíveis responsáveis pelo evento, catalogar os danos e a sua abrangência, bem como os elementos que possam evidenciar o nexo de causalidade.

No acidente provocado pelo rompimento da adutora da CEDAE, por exemplo, os Defensores Públicos do NUDECON-RJ foram imediatamente ao local do acidente para verificar o alcance dos danos. Muitas casas atingidas e destruídas foram visitadas com a autorização dos moradores, com o registro fotográfico dos prejuízos e a catalogação das necessidades imediatas das vítimas por meio do emprego de formulários específicos.

A presença dos Defensores Públicos no local do acidente confere especial sensação de proteção às vítimas, quase sempre pessoas em situação vulnerável. O contato direto das pessoas afetadas com os seus representantes torna real a promessa constitucional de tutela efetiva dos direitos, núcleo da garantia do acesso à justiça prevista no art. $5^{\circ}$, inciso XXXV, da Constituição da República. Além disso, a legitimidade da representação passa a ser qualificada pelo contato humano.

Com efeito, a legitimação adequada, fundamental para a defesa dos interesses das coletividades em juízo, deve ser entendida, nos dias atuais, como o resultado da efetiva 
aproximação entre representante e representado, entre o Defensor Público e o assistido, entre o Sindicato e os empregados, entre a Associação e os moradores, dentre outros exemplos, com o conhecimento, por parte daqueles, da realidade social em que vivem e trabalham estes, das suas reais necessidades e dos meios para supri-las de forma eficaz.

Nesse ambiente, as soluções de gabinete, formais, sempre ideais no papel, já não satisfazem à necessidade, cunhada pela realidade quase sempre amarga, de uma tutela humanizada dos interesses dos assistidos.

A racionalidade não instrumental entre os sujeitos, ${ }^{24}$ em especial a relação intersubjetiva entre os concernidos e os legitimados coletivos deve ser a inspiração almejada. A ação comunicativa é um pressuposto de validade e efetividade da solução coletiva construída pelos sujeitos participantes do processo coletivo, que deve se pautar pelo diálogo de todos na busca de um entendimento adequado. ${ }^{25}$

Outro benefício da inspeção local imediata é a possibilidade de se estabelecer contato com os demais órgãos públicos envolvidos no grande acidente de consumo, a exemplo do Corpo de Bombeiros, da Secretaria de Assistência Social, da Agência Reguladora, bem como com os representantes da empresa responsável e com as lideranças locais, como é o caso dos presidentes das Associações de Moradores, todos com um papel relevante a desempenhar na construção, conjunta e dialogada, da melhor solução.

\section{B) REPARAÇÃO JUSTA E ABRANGENTE}

A identificação dos critérios objetivos para a justa reparação dos prejuízos, por meio da pesquisa de parâmetros na jurisprudência para casos semelhantes, dentre outras, constitui o segundo pilar da iniciativa. Em sua estrutura não há espaço para a fixação desarrazoada do valor das indenizações.

No particular, não se pode ter como razoável qualquer forma de persuasão intersubjetiva instrumental para fins de imposição de soluções e valores inadequados de indenização para a situação concreta. A construção e a demonstração da proporcionalidade

\footnotetext{
${ }^{24}$ Sobre o tema, cf.: HABERMAS, Jürgen. Teoría de la acción comunicativa. Madrid: Taurus, v. $2,1992$.

${ }^{25}$ HANSEN, Gilvan Luiz. Conhecimento, verdade e sustentabilidade: perspectivas ético-morais em cenários contemporâneos. In: REBEL GOMES, Sandra Lúcia; NOVAIS CORDEIRO, Rosa Inês; MENDES DA SILVA, Ricardo Perlingeiro (Eds.). Incursões interdisciplinares: Direito e Ciência da Informação. Rio de Janeiro: Beco do Azougue, v. 1, p. 57, 2012.
} 
das medidas reparatórias exigem a efetiva deliberação das pessoas envolvidas à luz de critérios objetivos. ${ }^{26}$

Dessa forma, é preciso que a proposta de acordo ofereça uma ampla gama de proteção às vítimas e aos seus familiares, a partir das necessidades constatadas no mapeamento realizado na etapa anterior.

As indenizações para os danos materiais devem observar a ampla reparação dos prejuízos efetivamente comprovados pelas vítimas ou indicados em detalhamento realizado em conjunto com a Secretaria de Assistência Social ou por outro órgão público ou pessoa envolvidos.

As indenizações para os danos morais individuais devem ter em consideração, na fixação das possíveis faixas de valores, o escalonamento da gravidade do evento, que pode variar, por exemplo, conforme a lesão sofrida pela vítima tenha sido leve, média ou grave, alcançando os casos de mortes e outras repercussões, tudo a depender da hipótese concreta.

Há, também, preocupação com a fixação da indenização pelo eventual dano moral coletivo, com prioridade para que a sua reparação se dê in natura, com a entrega de benefícios diretos à comunidade impactada, sempre que possível.

Nos acidentes narrados no começo do estudo, os acordos firmados com a intermediação do NUDECON-RJ contemplaram, conforme o caso, por exemplo, o pagamento do tratamento de saúde para as vítimas, inclusive psicológico; o suprimento das suas necessidades urgentes, com a disponibilização imediata de uma quantia em dinheiro para a aquisição de itens de alimentação, vestuário e higiene pessoal; a aquisição de material escolar para as crianças afetadas; a alocação das famílias em abrigos ou hospedagens provisórios; a articulação com o Poder Público para a imediata vacinação da coletividade atingida, com o objetivo de preservar a saúde individual das vítimas; a articulação com o DETRAN para facilitar e acelerar os trâmites de emissão das segundas vias dos documentos de identidades, dentre outras medidas impostas pela realidade constatada por meio da inspeção referida no item anterior.

\footnotetext{
${ }^{26}$ Como ensina Emilo Santoro, "Uma comunidade cujos membros se recusam a reconhecer o critério da racionalidade e do significado independentes de cada contexto em que atuam, é uma comunidade irracional, governada pelo arbítrio e pela força, pela persuasão. Não é governada por normas que protegem a liberdade de todos, porque refletem a vontade de algum sujeito específico." SANTORO, Emilio et al. Estado de direito e interpretação: por uma concepção jusrealista e antiformalista do Estado de Direito. Porto Alegre: Livraria do Advogado, 2005, p. 45.
} 
A rápida identificação das necessidades para a entrega, também rápida, das respostas efetivas, constituem os traços marcantes do modelo que se busca difundir, sobretudo porque as vítimas, destinatárias finais dessas prestações urgentes, não podem, pela natureza delas, como se viu, esperar dias, semanas, meses ou até anos - nos casos de opção direta pela via judicial - pela resposta sem o agravamento do abalo da sua dignidade.

\section{C) BOA-FÉ E TRANSPARÊNCIA}

Guia a iniciativa, também como diretriz fundamental, a postura colaborativa dos representantes das partes envolvidas, orientada pela boa-fé na definição das bases para o acordo global, com o debate amplo sobre os diversos meios reparatórios que deverão ser empregados e os valores razoáveis das indenizações, sempre a partir da necessidade real das vítimas constatada nas etapas anteriores e do reconhecimento do nexo de causalidade com o acidente de consumo.

A transparência se destaca como essencial na medida em que a iniciativa pretende, às claras, coletar o máximo de informações disponíveis sobre o evento e aplicá-las no processo de negociação, para que as vítimas ou seus familiares, na etapa seguinte, possam bem compreender as propostas que serão formuladas, esclarecendo todas as eventuais dúvidas sobre a conveniência ou não da adesão individual ao acordo.

No acidente com os trens narrado acima, por exemplo, as indenizações foram fixadas depois de abrangente pesquisa da jurisprudência formada em casos semelhantes e as vítimas foram convidadas a comparecer na sede da Defensoria Pública para, primeiro, obter esclarecimentos sobre os termos do acordo global e comprovar a sua qualidade de vítima e a extensão dos danos sofridos, seguindo-se a oportunidade de escolha livre e consciente sobre a aceitação ou não dos termos da proposta individual.

\section{D) LIBERDADE DE ESCOLHA ORIENTADA}

De nada adiantariam a boa-fé dos representantes das partes e a ampla transparência assegurada pela iniciativa, como visto, se as vítimas ou os seus familiares fossem por qualquer meio induzidas ou forçadas a aceitar as propostas individuais formuladas.

Por isso é que, depois de estruturados os termos amplos do acordo, com as balizas gerais para o emprego dos diversos meios reparatórios, as vítimas ou os seus familiares 
devem ser convidados a receber os mais abrangentes esclarecimentos sobre a sua qualidade jurídica de vítima do acidente de consumo e os direitos dela decorrentes, por pessoas integrantes dos quadros da Defensoria Pública ou de outro legitimado coletivo, em conjunto ou não com representantes das empresas envolvidas, para que possam avaliar e decidir, também aqui assistidas adequadamente, se aceitarão receber as indenizações nos prazos fixados no acordo global e outorgar quitação à empresa responsável pelo pagamento, sem a necessidade do ajuizamento de ação judicial. ${ }^{27}$

O caráter absolutamente facultativo do acordo é evidenciado neste momento. As vítimas ou seus familiares devem ter plena consciência de que a elas é assegurado o amplo acesso à justiça, com a representação da própria Defensoria Pública, sempre que estiverem presentes os pressupostos autorizadores, por meio do ajuizamento de uma ação judicial de natureza indenizatória contra os responsáveis pelo acidente de consumo.

O exemplo do acidente com o ônibus ocorrido em Paraty foi paradigmático, no ponto. No coletivo havia vítimas locais, residentes em Paraty, vítimas que residiam na cidade do Rio de Janeiro e outras que residiam em São Paulo e que passavam férias na região da Costa Verde fluminense. $\mathrm{O}$ acesso às vítimas para a oferta dos esclarecimentos exigiu a elaboração de uma força tarefa, com o envolvimento de Defensores Públicos de mais de uma localidade, o deslocamento de alguns deles para a capital paulista, a realização de consultas e audiências por vídeo, dentre outras medidas, todas elas fundamentais para que as tratativas pudessem alcançar o resultado esperado.

\section{E) ENGAJAMENTO E VELOCIDADE DA RESPOSTA}

O sucesso do método decorre, por fim, do engajamento de todas as pessoas envolvidas e da velocidade na entrega das respostas efetivas aos prejudicados.

\footnotetext{
27 A exigência também é feita para a validade das chamadas claims resolution facilities. Nas palavras dos autores: "A opção por facilities privadas ou mistas como alternativa à propositura da demanda no Judiciário depende de que se garanta o "consenso informado" das partes. Isso vale tanto para os Estados Unidos quanto para o Brasil. Há necessidade de se assegurar assessoria técnica imparcial para os atingidos, seja através da advocacia pro bono (advogados pro bono, com honorários limitados, low-fee basis, ou defensores públicos), de grupos de trabalho (disaster response teams), ou, ainda, a possibilidade de impugnação judicial, individual ou coletiva, sempre que se verificar que a falta de consenso informado e conhecimento claro sobre a alternativa judicial está resultando em um prejuízo aos atingidos". CABRAL, Antonio do Passo; ZANETI JR., Hermes. Entidades de infraestrutura específica para a resolução de conflitos coletivos: as claims resolution facilities e sua aplicabilidade no Brasil. São Paulo: Revista de Processo, vol. 287, Jan/2019, p. 445-483.
} 
A atuação ética dos representantes das partes, orientada pela boa-fé, com a participação dos entes públicos responsáveis pela fiscalização das atividades e de eventuais outros legitimados à defesa dos interesses dos consumidores, permite a construção de uma solução extrajudicial abrangente, voltada a oferecer às vítimas e aos seus familiares o melhor resultado possível, no menor tempo disponível, sem que se faça necessária a ida ao Poder Judiciário e o aguardo, tormentoso, da sua resposta.

Ainda no exemplo da colisão dos trens, para ficar em um dos exemplos, o acordo global foi fechado em menos de 48 horas após o acidente e as vítimas começaram a receber as suas indenizações no prazo de 10 (dez) dias, a contar da validação dos documentos realizada em conjunto pela Defensoria Pública e pela empresa.

Salienta-se que a celeridade para a obtenção do ajuste, nos casos ora analisados, não acarretou perdas das garantias fundamentais do processo para os interessados, como bem observado por José Augusto Garcia de Sousa: ${ }^{28}$

Caso sejam muito enfatizadas a celeridade e a eficiência, podem sofrer perdas as garantias liberais do processo, como o contraditório e a ampla defesa. Nem sempre, porém, o dilema se materializará. Bom exemplo disso se vê em atuação prática desenvolvida pelo Núcleo de Defesa do Consumidor da Defensoria Pública do Estado do Rio de Janeiro (NUDECON), referente a grandes acidentes de consumo em serviços públicos delegados. [...] E o melhor é que essa resolução rápida para problemas coletivos complexos deriva de mecanismos compositivos extrajudiciais. Houvesse a necessidade da judicialização, certamente a solução integral só aconteceria, e de maneira imperfeita - no mínimo, alguns ou muitos beneficiários já teriam falecido -, décadas depois. Enfim, estamos diante de uma celeridade bastante sadia, sem comprometer valores potencialmente contrapostos.

\section{6 - AUSÊNCIA DE PERFEITO ENQUADRAMENTO NAS TÉCNICAS DA MEDIAÇÃO E DA CONCILIAÇÃO}

Do que se viu, o modelo cunhado com a participação da Defensoria Pública do Estado do Rio de Janeiro para a solução dos conflitos resultantes dos grandes acidentes de consumo não se enquadra facilmente nas molduras da mediação e da conciliação.

${ }^{28}$ SOUSA, José Augusto Garcia de. A tempestividade da justiça no processo civil brasileiro: repercussão no sistema, desenho constitucional e dimensão conflituosa. 1. ed. Salvador: Juspodivm, 2020, p. 370-371. 
Como é sabido, a mediação desempenha um relevante papel quando, entre as partes em conflito, há um vínculo duradouro, como nas relações familiares, na convivência cotidiana com os vizinhos, no emprego de determinado insumo na linha produtiva de uma fábrica, vínculo esse que, em muitos casos, não poderá ser rompido sem que surjam novos e maiores prejuízos.

Nesses casos, uma decisão imposta de fora, por um terceiro imparcial (juiz ou árbitro), dificilmente será uma boa decisão. Caberá às partes, portanto, com olhos no futuro da relação, com a ajuda do mediador, encontrar a solução média que permita resolver o conflito e seguir em frente, se possível sem rancores.

A conciliação segue trilha parecida, mas não pressupõe a existência de vínculo duradouro entre as partes. Também na conciliação o resultado será alcançado pelas próprias partes e não imposto por um terceiro imparcial. São bons exemplos as indenizações devidas pelos acidentes de trânsito.

Em tais casos, será relevante para o sucesso da conciliação a disposição dos envolvidos para ver na fruição de benefícios imediatos o necessário incentivo para o encerramento do conflito por meio da oferta de concessões recíprocas. O conciliador deve trabalhar, justamente, para revelar esses incentivos.

O modelo desenhado, caso a caso, para a solução dos conflitos coletivos nos grandes acidentes de consumo vale-se de técnicas da mediação e da conciliação, mas não se esgota nelas. $^{29}$

As características da atuação dos legitimados coletivos, com visitas imediatas aos locais do evento para mapeamento prévio das vítimas e dos danos; a extensão dos prejuízos e a sua íntima relação com as esferas mais caras à dignidade humana; o perfil quase sempre de vulnerabilidade das vítimas, a exigir proteção e o reequilíbrio de armas como corolário do amplo acesso à justiça; a ausência de concessões ou de renúncia a direitos nas etapas iniciais de formulação da estrutura da proposta global do acordo; e, ainda, o exercício de

\footnotetext{
${ }^{29}$ No caso da mediação, como uma forma extrajudicial de solução de conflitos, tem-se como regra uma resposta mais rápida e eficiente aos conflitos, além de mais democrática, pois a resposta é dada pelos próprios envolvidos. Outrossim, ela enseja a desjudicialização dos conflitos, o que tem ocorrido, inclusive durante as investigações preliminares dos fatos noticiados e que ensejariam a propositura de uma ação civil pública, mas que podem conduzir a um consenso entre as partes, quando, então, firma-se um termo de compromisso em respeito aos direitos dos cidadãos. Cf., sobre o tema: MADERS, Angelita Maria. $\mathrm{O}$ acesso à justiça nas relações negociais públicas e privadas: a tutela dos direitos difusos e coletivos pela defensoria pública por meio da ação civil pública. Revista do Direito Público, v. 6, n. 3, 2011, p. 36.
} 
papéis relevantes pelos representantes de diversos órgãos públicos, aliado ao efetivo comprometimento da empresa envolvida, dentre outras características, aproximam o modelo ora em estudo do chamado Desenho de Sistemas de Resolução de Disputas (Dispute System Design - DSD). ${ }^{30}$

Nessa perspectiva, preocupado com a adequação das propostas, com os custos envolvidos e com a tutela efetiva dos interesses em jogo, o método ora em estudo, ao viabilizar a customização das soluções para os conflitos resultantes dos grandes acidentes de consumo, a partir das exigências da situação concreta, em suas múltiplas vertentes, eleva a importância da aquisição imediata de informações, do diálogo produtivo entre as partes, da boa-fé e da transparência.

\section{7 - A IDENTIFICAÇÃO DAS CONTRAPARTIDAS: OS INCENTIVOS PARA AS EMPRESAS ENVOLVIDAS}

\footnotetext{
${ }^{30}$ Como afirma OSTIA, "pode-se conceituar o DSD como um método, baseado em princípios e técnicas, de customização de sistemas que possibilitem o procedimento e a solução mais adequada a um determinado conflito". OSTIA, Paulo Henrique Raiol. Desenho de sistema de solução de conflito: sistemas indenizatórios em interesses individuais homogêneos. Dissertação de mestrado. Faculdade de Direito da Universidade de São Paulo. São Paulo, 2014, p.91.

Sobre a aplicação da técnica nas grandes corporações, afirma M. Afzalur Rahim: "What we need for contemporary organizations is conflict management, not conflict resolution. Conflict management does not necessarily imply avoidance, reduction, or termination of conflict. It involves designing effective strategies to minimize the dysfunctions of conflict and enhancing the constructive functions of conflict in order to enhance learning and effectiveness of an organization". RAHIM, M. Afzalur. Managing conflict in organizations. 3rd ed. London: Quorum Books, 2001, p. 76.

Por outro lado, os objetivos aproximam o método ora em estudo, em certa perspectiva, das chamadas claims resolution facilities, que são, segundo os autores, "entidades ou mais genericamente infraestruturas criadas para processar, resolver ou executar medidas para satisfazer situações jurídicas coletivas que afetam um ou mais grupos de pessoas, que judicialmente seriam tratadas como milhares de casos individuais, casos repetitivos e ações coletivas", e que se destacam, dentre outras características, por contar com uma "flexibilidade no design dos procedimentos, o que permite a formulação de planos de atuação mais adequados, sem eliminar possibilidades de revisão desses planos dinamicamente, a partir de um constante feedback dos destinatários e grupos interessados, advogados e supervisores do Judiciário, retomando as discussões sobre o formato da facility e o design dos procedimentos em loops de reavaliação". CABRAL, Antonio do Passo; ZANETI JR., Hermes. "Entidades de infraestrutura específica para a resolução de conflitos coletivos: as claims resolution facilities e sua aplicabilidade no Brasil”. São Paulo: Revista de Processo, vol. 287, Jan/2019, p. 445483.

Para mais informações, cf.: MCGOVERN, Francis E. The What and Why of Claims Resolution Facilities. Stanford Law, Review, v. 57, 2005, p. 1361-1389. Disponível em: https://scholarship. law.duke. edu/faculty_ scholarship/ 1268. Acesso em 15 junho de 2020.
} 
Uma observação final: quais são os incentivos que podem levar uma empresa, identificada como a responsável pelo grande acidente de consumo, a efetuar o pagamento imediato das indenizações ou a adotar de uma série de providências reparatórias também imediatas, abrindo mão da judicialização das questões e do tempo de duração dos processos judiciais?

Os casos concretos expostos acima relevam alguns fatores que foram fundamentais para o engajamento da empresa responsável: a) a compreensão e tomada de consciência da responsabilidade que a empresa possui na comunidade em que está inserida; b) o reconhecimento da legitimidade do representante da coletividade afetada, com a possível resolução das questões e a consequente redução das chances de ajuizamento de ações judiciais coletivas; c) a reversão, imediata, dos rumos da cobertura do acidente de consumo pela mídia, que normalmente deixa de focar no acidente e nas suas causas a partir do anúncio público do acordo firmado, para se dedicar, em poucas notas, ao acompanhamento da efetiva reparação das vítimas, contribuindo para o reforço ou o resgate da imagem positiva da empresa junto ao seu público consumidor; d) a redução dos custos com a judicialização e o acompanhamento dos processos judiciais, individuais e coletivos, bem como com as incertezas que cercam os seus resultados; e) não havendo a judicialização de um grande número de ações individuais, há menos chance de se formar, no âmbito de atuação da empresa, junto ao Poder Judiciário local, uma jurisprudência que afirme a sua responsabilidade pelos eventos de igual natureza; e, sem esgotar o rol, f) a possibilidade de adequação do valor das indenizações pagas por meio do acordo às coberturas previamente estipuladas nas apólices de seguros firmadas pelas empresas.

O sucesso da iniciativa exige, ainda, com idêntica relevância, que o corpo jurídico da empresa, interno e contratado, tenha especial atenção aos incentivos que cercam às propostas de acordo bem estruturadas a partir das necessidades geradas pelos grandes acidentes de consumo, para que, no desempenho do seu mister, possa orientar a diretoria e os responsáveis últimos pela tomada de decisão no sentido de defender os melhores interesses da empresa.

É passado o tempo de a intransigência apaixonada dar lugar à postula colaborativa. A mesa de negociação deve passar a ser encarada como uma aliada para a busca dos melhores resultados pelos gestores das empresas envolvidas nos acidentes de consumo, e não como uma demonstração de fraqueza ou um atestado de culpa. 


\section{8 - CONSIDERAÇÕES FINAIS}

A tomada de consciência, a cada dia mais presente na sociedade contemporânea, de que ao Poder Judiciário não deve ser confiada, como primeira e única opção, a solução de todos os conflitos de interesses, devendo as partes neles envolvidas se esforçarem, sempre que possível, para a construção de soluções consensuais, impõe a adoção de iniciativas e o desenvolvimento de metodologias que possam entregar respostas rápidas e satisfatórias, que tutelem os direitos de forma adequada.

Os casos analisados ao longo do presente estudo e os bons resultados alcançados com a customização das soluções consensuais para os conflitos resultantes dos grandes acidentes de consumo ocorridos no Estado do Rio de Janeiro no último lustro comprovam que o rompimento da inércia e o efetivo engajamento das pessoas envolvidas podem promover mudanças efetivas na forma de proteção dos direitos das vítimas dos grandes acidentes de consumo.

Fica o convite ao diálogo e à reflexão sobre as vantagens (e as desvantagens) que as tentativas de construção de soluções customizadas para os conflitos que envolvam um grande número de vítimas podem produzir.

\section{REFERÊNCIAS}

ARAÚJO, Nadia de; FÜRST, Olivia. Um exemplo brasileiro do uso da mediação em eventos de grande impacto: o programa de indenização do voo 447. Revista de Direito do Consumidor, vol. 91/2014, p. 337, Jan/2014.

CABRAL, Antonio do Passo; ZANETI JR., Hermes. Entidades de infraestrutura específica para a resolução de conflitos coletivos: as claims resolution facilities e sua aplicabilidade no Brasil. São Paulo: Revista de Processo, vol. 287, Jan/2019, p. 445483.

FOUCAULT, Michel. Microfísica do Poder. 26. ed. São Paulo: Graal, 2013.

GIDI, Antonio. A class action como instrumento de tutela coletiva dos direitos. São Paulo: Revista dos Tribunais, 2007. 
GRINOVER, Ada Pellegrini; MENDES, Aluísio Gonçalves De Castro; WATANABE, Kazuo. Direito processual coletivo e o anteprojeto de código brasileiro de processos coletivos. São Paulo: Revista dos Tribunais, 2007.

HABERMAS, Jürgen. A crise de legitimação no capitalismo tardio. Tradução de Wamireh Chacon. Rio de Janeiro: Tempo Brasileiro, 1980.

Teoría de la acción comunicativa. Madrid: Taurus, v. 2, 1992.

HANSEN, Gilvan Luiz. Conhecimento, verdade e sustentabilidade: perspectivas éticomorais em cenários contemporâneos. In: REBEL GOMES, Sandra Lúcia; NOVAIS CORDEIRO, Rosa Inês; MENDES DA SILVA, Ricardo Perlingeiro (Eds.). Incursões interdisciplinares: Direito e Ciência da Informação. Rio de Janeiro: Beco do Azougue, v. 1, p. 55-76, 2012.

HÖFFE, Otfried. A Democracia no mundo de hoje. Tradução de Tito Lívio Cruz Romão. São Paulo: Martins Fontes, 2005.

LANGER, Octaviano. A tutela coletiva como instrumento de acesso à justiça. Revista Eletrônica Direito e Política, v. 5, n. n. 2, p. 191-216, 2010.

LEAL, Leonardo José Peixoto. Acidentes de consumo e resolução extrajudicial. Trabalho publicado nos Anais do XVIII Congresso Nacional do CONPEDI, realizado em São Paulo/SP nos dias 04, 05, 06 e 07 nov/2009.

MADERS, Angelita Maria. O acesso à justiça nas relações negociais públicas e privadas: a tutela dos direitos difusos e coletivos pela defensoria pública por meio da ação civil pública. Revista do Direito Público, v. 6, n. 3, p. 21-38, 2011.

MCGOVERN, Francis E. The What and Why of Claims Resolution Facilities. Stanford Law, Review, v. 57, 2005, p. 1361-1389. Disponível em: https://scholarship.law. duke. edu/faculty_scholarship/1268. Acesso em 15 junho de 2020.

MILLNS, Susan. Respect for human dignity: an Anglo-French comparison. 2004. Doutorado - University of Kent at Canterbury, Canterbury, 2004.

MORAES, Marcos Vinicius Malheiros. GENEALOGIA - MICHEL FOUCAULT. Enciclopédia de Antropologia. São Paulo: Universidade de São Paulo, Departamento de Antropologia, 2018. Disponível em: <http://ea.fflch.usp.br/conceito/genealogiamichel-foucault>. Acesso em 10 abril de 2020. 
OSTIA, Paulo Henrique Raiol. Desenho de sistema de solução de conflito: sistemas indenizatórios em interesses individuais homogêneos. Dissertação de mestrado. Faculdade de Direito da Universidade de São Paulo. São Paulo, 2014

PERELMAN, Chaïm; OLBRECHTS-TYTECA, Lucie; COELHO, Fábio Olhôa. Tratado da argumentação: a nova retórica. Martins Fontes, 1996.

RAHIM, M. Afzalur. Managing conflict in organizations. 3rd ed. London: Quorum Books, 2001.

SANTORO, Emilio et al. Estado de direito e interpretação: por uma concepção jusrealista e antiformalista do Estado de Direito. Porto Alegre: Livraria do Advogado, 2005.

SOUSA, José Augusto Garcia de. A tempestividade da justiça no processo civil brasileiro: repercussão no sistema, desenho constitucional e dimensão conflituosa. 1. ed. Salvador: Juspodivm, 2020. 